\title{
Non-Valvular Atrial Fibrillation: Diagnostic and Therapeutic Aspects About 45 Cases in a Cardiology Department of Sikasso Hospital in Mali
}

\author{
Traore Abdoulaye Kissima ${ }^{1}$, Sangaré Zoumana ${ }^{1,2}$, Doumbia Modibo' ${ }^{1}$, Mingou Joseph Salvador ${ }^{2 *}$, Sanogo \\ Drissa $^{1}$, Birwe Leon ${ }^{1}$, Traore Ousmane ${ }^{1}$, Traore Salia ${ }^{1}$, Dioma Elie ${ }^{1}$, Sarr Simon Antoine ${ }^{2}$, Bodian Malick ${ }^{2}$ and \\ Kane Adama ${ }^{3}$
}

${ }^{1}$ Department of Cardiology, Regional Hospital of Sikasso, Sikasso, Mali

${ }^{2}$ Department of Cardiology, Teaching Hospital Aristide Le Dantec, Dakar, Senegal

${ }^{3}$ Department of Cardiology, Regional Hospital of Saint Louis, Saint Louis, Senegal

Submission: November 01, 2018; Published: December 10, 2018

*Corresponding author: Joseph Mingou, Department of Cardiology, Teaching Hospital Aristide Le Dantec, Dakar, Senegal

\section{Abstract}

Introduction: Atrial Fibrillation (AF) is the more common cardiac arrhythmia encountered in clinical practice. It is responsible of a real public health problem due to his high incidence and increase.

Aim: Describe the diagnostic and therapeutic aspects of non-valvular atrial fibrillation.

Methods: It was a descriptive cross-sectional study during a period of two years from October 1st, 2014 to September 30th, 2016. Were included in the study patients with atrial fibrillation hospitalized at the cardiology department of Sikasso hospital in Mali.

Results: Forty-five patients were includes with a hospital rate of 3.33\%. The mean age was 45 year (30-89 years) with a sex ratio of 0.66. Symptoms were dominated by those of heart failure (42.2\%). Persistent atrial fibrillation was more frequent. Subjacent cardiopathy was dominated by hypertensive heart disease $(51,1 \%)$ follow by dilated cardiomyopathy $(15,5 \%)$. Tachycardia was noticed at admission in $71,6 \%$ cases. Echocardiography noted a left atrium dilatation in 33,8\% of case, an alteration of left ventricular fraction ejection in $37.8 \%$. The CHA2DS2VASc score of 2 or higher was found in 72,6\% of patient and the HAS-BLED score of 3 or higher was found 3 in $13 \%$. The anticoagulation therapy was prescribed in $92,7 \%$ of case in whom vitamin $\mathrm{K}$ antagonist was used in $87,2 \%$. Digoxin was prescribed in $78 \%$, beta-blockers in $11 \%$ and calcium canal blocker in 3\%. Nine dot eight percent of case were given a direct cardioversion treatment in 3,12\% or electrical treatment in $6.68 \%$. Among the latters, a sinus rhythm was restored in 7, 35\% case. Complications were dominated by heard failure (52\%) followed by thromboembolic events $(17,8 \%)$. The mean of the hospital's duration was 9 days and the rate of mortality of $3.6 \%$.

Conclusion: Our work has come to point out the occurrence of non-valvular AF in young people, the weight of hypertensive heart disease, the high thrombotic risk level and also the significant usage of digoxin.

Keywords: Non-valvular atrial fibrillation; Hypertensive heart disease; Sikasso (Mali)

\section{Introduction}

Atrial Fibrillation (AF), particularly the non-valvular form represents an actual problem in the cardiological environment because of its incidence and his severity related to multiple complications particularly in senior citizen with polypathology [1].

Often associated with all forms of heart disease, AF occurs frequently during an evolution of a mitral valvular disease, affecting $30-50 \%$ of patients with a surgical indication [1].

Its incidence increases with age, corresponding to $2 \%$ above 60 years of and $8-10 \%$ above 75 years of age [2]. It was higher in men than women according to some authors, overall mortality and cardiovascular mortality were twice more important in patients with $\mathrm{AF}$ than in general population [2]. Non-valvular AF is common at the same time (80\% of FA in Europe), affecting 3-5 $\%$ of people over 60 year of age and it is a potent risk factor of ischemic stroke ( $5 \%$ per year about five time higher than patients without AF) [3-5].

It affects 2.4 million of people in the United State and 6 million in Europe [6]. It represents 7,1 hospital Aristide Le Dantec, \% rate of hospitalisation in Congo [7]. In the cardiology department hospital, we found during the period of 2006 to 2007 an incidence of $17 \%$ of $\mathrm{AF}$ corresponding to $68 \%$ of all cardiac arrhythmia disorder [8]. In Mali, the non-valvular AF represented $11.39 \%$ of rate of hospitalisation in the cardiology department of Gabriel TOURE University Hospital in 2012 [9]. The mortality rate is $23 \%$ 
per month, versus $8 \%$ in patients with sinus rhythm. Among monthly survivors the annual mean of relapse was about $10 \%$ and the overall mortality rate is multiplied by a factor of 2 [2].

Several studies has been done on AF in Sub-Saharan Africa, but very few were focused specifically on the non-valvular form $[7,10]$. Its management is often limited because of the lack of technical platform $[8,9]$.

\section{Methods}

It was a descriptive cross-sectional study conducted during a period of two years from October $1^{\text {st }}, 2014$ to September $30^{\text {th }}$, 2016 in patients hospitalized for a non-valvular AF.

The diagnostic was led by an electrocardiogram performed. The Thrombotic risk was assessed by the CHA2DS2VASc score and the haemorrhagic risk by HAS-BLED score. All participants are volunteers and ethical considerations were taken into account. The studied Parameters used concerned epidemiological, clinical, paraclinic, therapeutic and evaluative data. Data were collected in a pre-established survey sheet and transcribed in a database using EXCEL version 2010 software. Data analysis were performed using the SPSS version 20 software.

\section{Results}

Forty-five patients were included with a hospital's incidence of $3.33 \%$. the mean age was 45 year (30-89years) and a sex ratio of 0.66 . Symptoms were dominated by those of heart failure (42,2\%). Persistent AF were more frequent (68,42\%). Subjacent cardiopathy was dominated by hypertensive heart disease $(51,1 \%)$ followed by dilated cardiomyopathy $(15,5 \%)$ (Table 1$)$. Among extra cardiac causes, hyperthyroidism represented 3.5\% of case, tachycardia was noticed at admission in $71.6 \%$ patients. The mean of heart rate on the electrocardiogram was 102.8 beats per minute with repolarization disorders in $40 \%$.

Table 1: Repartition of patients according to the existence or not of a subjacent cardiopathy.

\begin{tabular}{|c|c|c|}
\hline Personal history & Effective & percentage \\
\hline Hypertension & 2 & 4,4 \\
\hline Hypertensive cardiopathy & 23 & 51,1 \\
\hline cardiomyopathy & 7 & 15,7 \\
\hline Pericarditis & 2 & 4,4 \\
\hline Chronic pulmonary heart & 3 & 6,6 \\
\hline Ischemic cardiopathy & 4 & 8,9 \\
\hline Healthy heart & 4 & 8,9 \\
\hline Total & 45 & 100,0 \\
\hline
\end{tabular}

Echocardiography has noted a dilatation of the left atrium in $33.3 \%$ of case (Figure 1), an alteration of ventricular ejection fraction in $37.8 \%$. The CHA2DS2VASc score was 2 or higher in $72.6 \%$ and HAS-BLED was 3 or higher in $13 \%$ of patients.

Figure 1: Reparation of patients according to echocardiography data.
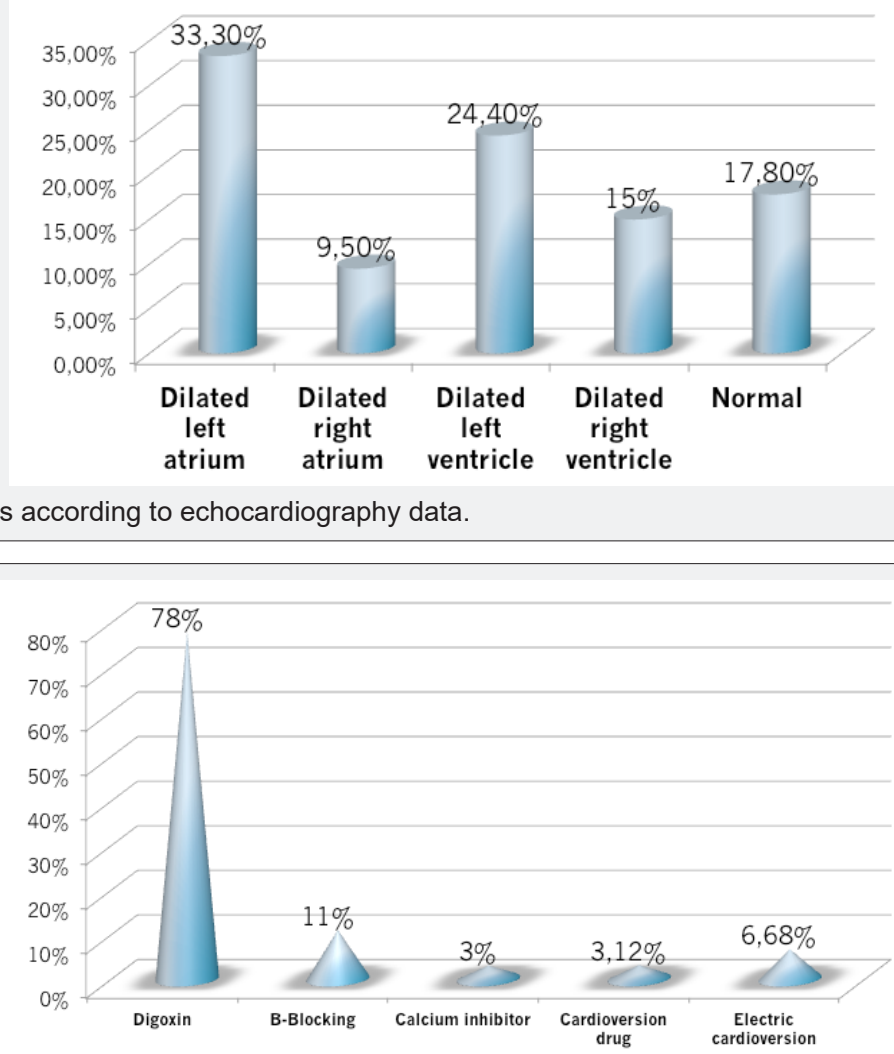

Figure 2: Repartition of patients according to therapeutic. 
The anticoagulation therapy was prescribed in $92,7 \%$ of case in whom vitamin $\mathrm{K}$ antagonist was used in $87,2 \%$. Digoxin was prescribed in $78 \%$, beta-blockers in $11 \%$ and calcium canal blockers in 3\% (Figure 2).

Nine dot eight percent of case were given a direct cardioversion treatment in 3,12\% or electrical treatment in $6.68 \%$. Among the latters, a sensual rhythm was restored in 7, 35\% case. Complications were dominated by heard failure $(52 \%)$ followed by trombo-embolic incidence $(17,8 \%)$. The Mean of hospital's duration was 9 days (3-14 days) and the rate of mortality was $3.6 \%$.

\section{Discussion}

Non-valvular AF represents $61 \%$ of all cardiac arrhythmia [11]. In our study, it represented $70 \%$ of all cardiac arrhythmia with a hospital prevalence of $3.33 \%$. The mean age in our series was 45 year with an extremes of 30 and 89 years. This result is near from this one of Lamoudi Prisca who found a mean age of 67, $36+/-12,23$ year [11]. This difference could be explained by the duration and the place of the study.

Women were more represented than men in our study with a sex ratio of 0.6. This result is similar to the one of Lamoudi Prisca in Dakar [11]. This would be explained by the multiplicity of cardiovascular risk factor and the fact that rate of women is higher than that of men $(60 \%$ vs. $40 \%)$ in general population and also the fact that women live longer and attended the more health maintenance center than men. Hypertension was the risk factor the more represented $(51,1 \%)$. This is similar to Framingham survey which noted less $50 \%$ [12]. Hyperthyroidism was found in $3.5 \%$ as non-cardiac causes; this result was similar to this one of Lamoudi Prisca [11] in Senegal 3,6\%.

The mean of heart rate was 102.8 beats per minute (42-209 beats per minute); Lamoudi in Senegal in 2009 found 108 beats/ minute (40 à 180 beats/minute) [11].

The Most represented Echocardiographic abnormalities were left atrium dilatation in $33.3 \%$ of case. The high incidence of left atrium dilatation was reported in the majority of studies $[13,14]$. In fact, the association between the left atrial dilatation and the onset of AF is classical. In fact, the more the left atrium is dilated, the risk of $\mathrm{AF}$ occurrence is important.

Hypertensive heart disease represented $51.1 \%$ in our series. Chahir IT [8] found 23\% in Senegal, Mbolla [7] in found 33, 6\% in Congo. This high frequency could be explained by the delay of diagnosis linked to patient's lack of knowledge of their state of health and to difficulties to access to medical care.

Electrical and drug resinusalization has been observed in $7.35 \%$ ( 5 cases) versus 9 cases in a study by Chahir IT [8]. Thromboembolic complications represented $17.8 \%$ in our study of witch $12.71 \%$ ischemic stroke. Chahir IT in his study found $15 \%$ [8] and the Framingham survey [15] reported 15 to $20 \%$. This difference could be explained by the size of the samples, the age of patients, but also the delay of the diagnosis in our area.
The mortality rate was $3.6 \%$ versus $4.2 \%$ reported in a study by Lamoudi Prisca [11].

\section{Conclusion}

Non-valular AF is a common public health problem because of its high prevalence and also the complexity of its management. Hypertension is as far the most incriminated risk factor in the occurrence of AF because of his multifactorial nature.

Despite the panoply of methods used in his management, it is enamelled by the occurrence of redoubtable complications.

Our study has come to point out the occurrence of nonvalvular $\mathrm{AF}$ in young in, the weight of hypertensive heart disease and the high of thrombotic risk level but also the significant use of digoxin. It is responsible for a large number of death so it would be useful to diagnose it soon, and a strict and codified management is needed.

\section{Conflict of Interest}

Authors have none to declare.

\section{References}

1. Sliwa K, Wilkinson D, Hansen C, Ntyintyane L, Tibazarwa K, et al (2008) Spectrum of heart disease and risk farctors in a black urban population in south Africa (the Heart of Soweto Study): a cohort study. Lancet 371(9616): 915-922.

2. Sztajzel J, Stalder H (2003) Fibrillation auriculaire. Primary Care 3: 695-699.

3. Mas JL (1995) Complications thromboemboliques au cours de la fibrillation auriculaire non valvulaire. La revue du praticien 45: 935941.

4. Buyukoglu B, Cohen A (1999) Fibrillation auriculaire et d'accident vasculaire ischémique : les études SPAF et après. Sang Thrombose Vaisseaux 11(7): 538-547.

5. Henry P, Leenhardt A (2002) Troubles du rythme cardiaque à la phase aigue des AVCI. Correspondances en neurologie vasculaire 4: 22-25.

6. Gersh BJ, Tsang TSM, Barne ME, Seward JB (2005) The changing epidemiology of non-valvular atrial fibrillation : the role of novel risk factors. European Heart Journal 26: 5-11.

7. Mbolla BF, Gombet T, Ikama MS, et al. (2006) Fribrillation auriculaire a propos de 131cas Congolais. Med Afr Noire 5302: 73-78.

8. Chahir IT (2007) Prise en charge hospitalière de la fibrillation auriculaire. Données épidémiologiques et stratégies thérapeutiques, à propos de 100 patients consécutifs hospitalisés à la clinique cardiologique du CHU Aristide Le Dantec. Mémoire Med, Dakar.

9. Coulibaly B (2012) Prévalence de la fibrillation auriculaire en milieu spécialisé cardiologique. Mémoire Med, Bamako.

10. Levy S, Sbrgia P (2005) Remodelage dans la fibrillation auriculaire. Archives des maladies du cœur et des Vaisseaux 98: 308-310.

11. Thiombiano LP (2009) Fibrillation auriculaire non valvulaire dans le service de Cardiologie de l'hôpital général Grand Yoff. Thèse Med, Dakar, Senegal.

12. Desmos M, Hagege A, Guillerm F (2002) Cardiomyopathie dilatée et grossesse. 7ème congrés de médecine fotale 7: 1-8.

13. Lascault G (1992) Fibrillation auriculaire et flutter auriculaire: étiologie, physiopathologie, diagnostic, évolution, pronostic, principe du traitement. Revue du praticien 42: 497-504. 
14. Lévy S, Breithardt G, Campbell RW, Camm AJ, Daubert JC, et al. (1998) Atrial fibrillation: current knowledge and recommendations for management. Working Group on Arrhythmias of the European Society of Cardiology. Eur Heart J 19(9): 1294-1320.
15. Lousberg P, Melon P, Waleffe A, et al. (2004) La fibrillation auriculaire paroxystique. Revue médicale de Liège 59: 255-302.

Your next submission with Juniper Publishers
will reach you the below assets
- Quality Editorial service
- Swift Peer Review
- Reprints availability
- E-prints Service
- Manuscript Podcast for convenient understanding
- Global attainment for your research
- Manuscript accessibility in different formats
( Pdf, E-pub, Full Text, Audio)
- Unceasing customer service
Track the below URL for one-step submission
https://juniperpublishers.com/online-submission.php

